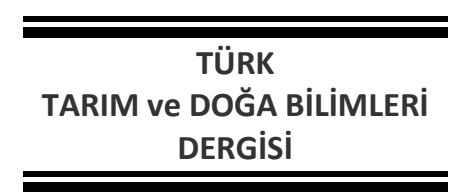

TÜRK

DERGISI

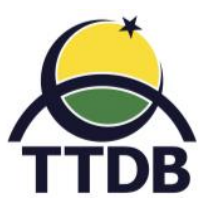

www.dergipark.gov.tr/turkjans

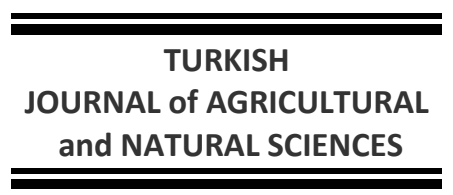

Araştırma Makalesi

\title{
Biyokömür ve Kükürt Uygulamasının Alkali Killi-Tınlı Topraklarda Fosfor Alınabilirliği ve Toprak Enzim Aktivitesi Üzerine Etkileri
}

\author{
Veysel TURAN*
}

Bingöl University, Faculty of Agriculture, Department of Soil Science and Plant Nutrition, Bingöl, 12000, Turkey

*Corresponding author: vturan@bingol.edu.tr

Biyokömür adı verilen "biochar (BC)" zengin besin elementi içeriğine ve toprak ıslah edici özelliklere sahiptir. BC son zamanlarda gübre veya toprak düzenleyici materyal olarak kullanılmaktadır. Ancak BC'nin kükürt (S) ile birlikte uygulandığı çalışmalar sınırlıdır. Bu çalışma ile zeytin posasından elde edilmiş BC ve S'in ayrı ayrı ve birlikte uygulanmasının killi-tınlı ve pH si yüksek olan topraklarda fosfor (P) elverişliliği ile toprak sağlığı açısından önemli olan enzim aktiviteleri (asit fosfataz, alkalin fosfataz, $\beta$-Glukozidaz ve dehidrogenaz) üzerine etkileri araştırılmıştır. Topraklara farklı BC (0, \% 0.75, \% 1.5) ve S $\left(0,800 \mathrm{mg} \mathrm{kg}^{-1}\right)$ dozları uygulanarak kontrollü şartlarda faktöriyel deneme planına göre 45 gün süre ile inkübasyona bırakılmıştır. Bu çalışma sonuçlarına göre; elektriksel iletkenlik (EC), Toplam $P$ ve $\beta$-glukozidaz enzim aktivitesi üzerine $B C$ ve $S$ interaksiyonu önemli bulunmuştur. BC'nin, S ile birlikte uygulanması toplam fosfor miktarını artırırken, hem BC hem de $S$ uygulamaları elverişli P miktarını artırmıştır. Bununla birlikte, BC ve $S$ toprak $E C$ değerinde artışa neden olurken $S$ uygulaması toprak $\mathrm{pH}$ değerini düşürmüştür. Ek olarak, toprak organik madde miktarı BC dozunun artmasıyla yükselmiştir. Dikkat çekici bir şekilde BC ve $S$ uygulamaları; asit fosfataz, alkalin fosfataz ve dehidrogenaz enzim aktivitesi üzerine etki yapmazken, BC uygulaması yapılmayan $S$ uygulamasında $\beta$-glukozidaz enzim aktivitesi azalmıştır. Bu ön çalışma BC ve $S$ uygulamalarının arazi koşullarında ve uygun dozlarda çalışılmasının zorunlu olduğunu göstermektedir.

Anahtar kelimeler: Toprak Enzim aktivitesi, fosfor elverişliliği, zeytin posası biyokömürü.

\section{Effects of Biochar and Sulfur amendment on Soil Phosphorus and Soil Enzyme Activity in Alkaline Clay-Loam Soil}

\begin{abstract}
Biochar (BC) has rich nutrient content and soil-improving properties. BC has recently been used as a fertilizer or soil amendment material. However, studies in which BC is applied with sulfur (S) are limited. In this study, effects of BC obtained from olive pulp and $S$ separately and in combination with phosphorus (P) in soil with clay loam and high $\mathrm{pH}$ effects on enzyme activities -important for soil health- (acid phosphatase, alkaline phosphatase, $\beta$ Glucosidase and Dehydrogenase) have been examined. Different BC $(0,0.75 \%, 1.5 \%)$ and S $\left(0,800 \mathrm{mg} \mathrm{kg}^{-1}\right)$ doses have been applied to the soil and incubated under controlled conditions for 45 days according to the factorial trial plan. According to the results of this study, BC and $S$ interaction on electrical conductivity (EC), Total P and $\beta$ Glucosidase enzyme activity were found to be significant. BC and $S$ application increased the total phosphorus amount, while both $\mathrm{BC}$ and $\mathrm{S}$ applications increased the available amount of $\mathrm{P}$. However, BC and S resulted in an increase in soil EC value and $\mathrm{S}$ application decreased soil $\mathrm{pH}$ value. In addition, the amount of soil organic matter increased with the increase in the dose of BC. Strikingly while BC and S applications did not affect enzyme activity acid phosphatase, alkaline phosphatase and dehydrogenase, $\beta$-glucosidase enzyme activity was decreased in $S$
\end{abstract}


application without $B C$ application. This preliminary study shows that $B C$ and $S$ applications are required to be studied at appropriate field conditions and at appropriate doses.

Key words: Soil enzyme activity, phosphorus availability, olive pulp biochar.

\section{Giriş}

Dünyadaki fosfor $(P)$ kaynakları en fazla gübre olarak kullanılmaktadır. Bu rezervlerin gelecekte de tarımsal verimin arttırımasında etkili bir şekilde kullanılması anahtar rol oynayacağından ve aynı zamanda dünyada $\mathrm{P}$ kaynaklarının sınırlı olmasından dolayı gelecekte $P$ kaynaklarının tükenmesi beklenmektedir (Cordell ve ark., 2009; Sun ve ark., 2018). 2100 yılına kadar ekstrakte edilebilir fosfat kayalarının \%20-60 oranında azalacağı tahmin edilmektedir (Van Vuuren ve ark., 2010). Ancak, tarımsal alanlarda kaya fosfatların kullanılması ötrofikasyon gibi çevresel kaygılara yol açabilir (Carpenter, 2008). Bu nedenle, tarımsal P girdilerinin daha sürdürülebilir ve çevre dostu bir şekilde yönetimi acilen gereklidir (Cordell ve ark., 2009; Sonmez ve ark., 2016).

Biochar (BC) kontrollü şartlar altında ve oksijene sınırlı ortamda organik materyallerin proliz sonucu ayrışması sonucu oluşmaktadır (Lehmann ve Joseph, 2015). Değerli bir ürün olan BC; alkaline, yüksek seviyede karbon, geniş yüzey alanı, içerdiği zengin $\mathrm{N}, \mathrm{P}, \mathrm{K}$ ve birçok besin içeriğine sahiptir (Khadem ve Raiesi, 2019; Lehmann ve Joseph, 2015). Biochar aynı zamanda içerdiği kül bileşimleri ile toprakların kimyasal özelliklerinin iyileştirilmesinde etkili bir şekilde kullanılmaktadır (Lehmann ve ark., 2011; Turan ve ark., 2018b, 2018a). BC aslında toprağın üzerindeki doğrudan değişikliklerin yanı sıra, toprağın fiziksel özelliklerini etkileyerek bitki kök bölgesi üzerindeki toprağın mikrobiyal durumunu etkilemektedir (Ding ve ark., 2016) BC ayrıca alkaline özellikte olduğundan dolayı toprak pH'sını artırmakta ve bu artış bazı mikroorganizma faaliyetlerini etkilemektedir (Rousk ve ark., 2010). Toprak enzimleri organik maddenin ayrışmasında ve besin döngüsünde kilit rol üstlenmektedir. Bailey ve ark., (2011) yapmış oldukları bir çalışmada BC uygulamasıyla $\beta$ - glukozidaz enzim aktivitesinin toprak tipine göre farklılık gösterdiğini ifade etmişlerdir. Bununla birlikte alkalin fosfataz (AlkP) ve asit fosfataz (AcdP) enzim aktivitesi toprakta fosforik asidin anhidre olmasında katalizör görevi görmektedir. Bu nedenle bitki $P$ besin alımı ve organik $P$ mineralizasyonunda önemli rol oynamaktadır (Dick ve ark., 2000). BC uygulamasının AlkP aktivitesi üzerine yapılan çalışmalarda; (Akça ve Namlı, 2015) AlkP ve AcdP aktivitesini arttığını (Noyce ve ark., 2017), AlkP aktivitesini azalttığını, (Zhang ve ark., 2017) ise AlkP aktivitesini etkilemediğini belirtmişlerdir. Wu ve ark. (2013) yapmış oldukları çalışmada BC uygulamasının dehidrogenaz (DH) enzim aktivitesini etkilemediğini ifade ederken, Khadem ve Raiesi (2019) uygulanan BC üretim şekline bağlı olarak DH enzim aktivitesini arttırdığını ifade etmişlerdir.

Elementel kükürt (S) toprak $\mathrm{pH}$ oranın düşürülmesinde rol oynamakta ve bu da bitki besin elementlerinin alınımı için uygun koşullar oluşturmaktadır (Jaggi ve ark., 2005). Bustamante ve ark. (2016) yapmış oldukları bir çalışmada $S$ ve yeşil atık kompost uygulamalarının toprağın alınabilir $P$ miktarını artırdığı ifade etmişlerdir. Islam, (2012) yapmış olduğu bir çalışmada farklı dozlarda S formu ve dozu uygulamasının nohutta tohum verimini \%17 oranında arttırdığı ve bitkiler aracılığıyla mikro element alınımının yükseldiğini ancak $\mathrm{pH}$ oranını etkilemediğini ifade etmiştir. Literatüre göre $B C$ ve $S$ uygulamalarının yalnız bir şekilde uygulandığı birçok çalışma olmasına rağmen alkali ve killi-tınlı topraklarda zeytin posasından üretilen $B C$ ve $S$ ile birlikte uygulanması ile ilgili olarak çalışmalar sınırlıdır.

Bu çalışmanın amacı zeytin posasından elde edilmiş $B C$ ve $S^{\prime}$ nin ayrı ayrı ve birlikte uygulanmasının killi-tınlı ve $\mathrm{pH}$ sı yüksek olan topraklarda fosfor biyoelverişliliği ile toprak sağıı̆̆ açısından önemli olan enzim aktiviteleri üzerine etkilerini belirlemektir. Bu amaçları yerine getirmek için; toprakların $\mathrm{pH}, \mathrm{EC}$, organik madde, elverişli ve toplam fosfor, C, N, P ile ilgili 4 önemli enzim aktivitesindeki (asit fosfataz, alkalin fosfataz, $\beta$-Glukozidaz ve dehidrogenaz enzim aktivitesi) değişimler incelenmiştir.

\section{Materyal ve Yöntem \\ Toprak örnekleme ve deneme kurulumu}

Bu araştırmada kullanılan toprak Tokat ili Erbaa ilçesinden 0-15 cm derinliğinden 2018 yılı kaşım ayında toplanmıştır (Türkiye: $40^{\circ} 41^{\prime} 41.4 \mathrm{~N} \mathrm{~N}$ $\left.36^{\circ} 33^{\prime} 45.6^{\prime \prime} \mathrm{E}\right)$. Denemeye başlamadan önce topraklar $2 \mathrm{~mm}$ lik elekten geçirilerek içerisindeki tas ve bitkisel atıklar uzaklaştırımıştır Topraklar alkali özellik göstermekte olup kumlu bir tekstüre sahiptir. Denemede kullanılan biochar, zeytin posasından elde edilmiştir. Ayrıca denemede kullanılan toprak ve biochar fizikokimyasal özellikleri Tablo 1 de gösterilmiştir. 
Türk Tarım ve Doğa Bilimleri Dergisi 6(3): 527-535, 2019

Tablo 1. Denemede kullanılan toprağının ve zeytin posasından elde edilen Biochar materyalinin bazı fizikokimyasal özellikleri

\begin{tabular}{llllll}
\hline Özellik & & Değer & Biochar & Değer \\
\hline Kum & $\%$ & 41.40 & $\mathrm{pH}$ & - & 9.24 \\
Silt & $\%$ & 30.04 & $\mathrm{EC}$ & $\mathrm{dS} \mathrm{m} \mathrm{m}^{-1}$ & 1.06 \\
Kil & $\%$ & 28.56 & $\mathrm{C}$ & $\%$ & 67.91 \\
Tekstür & - & Killi-Tınlı & $\mathrm{N}$ & $\%$ & 1.86 \\
$\mathrm{pH}$ & - & 8.09 & $\mathrm{H}$ & $\%$ & 4.97 \\
$\mathrm{EC}$ & $\mathrm{dS} \mathrm{m}{ }^{-1}$ & 0.108 & $\mathrm{P}$ & $\%$ & 1.05 \\
Organik madde $_{\mathrm{CaCO}_{3}{ }^{\mathrm{b}}}$ & $\%$ & 1.45 & & & \\
$\mathrm{P}^{\mathrm{c}}$ & $\%$ & 11.81 & & & \\
$\mathrm{~K}^{\mathrm{d}}$ & $\mathrm{mg} \mathrm{kg}^{-1}$ & 9.51 & & \\
Toplam P & $\mathrm{mg} \mathrm{kg}^{-1}$ & 156.79 & & & \\
\hline
\end{tabular}

${ }^{\mathrm{a}}$ EC Elektriksel iletkenlik, ${ }^{\mathrm{b}} \mathrm{CaCO}_{3}$ kires, ${ }^{\mathrm{c}} \mathrm{P}$ Elverişli Fosfor, ${ }^{\mathrm{d}} \mathrm{K}$ Alınabilir Potasyum.

Kumlu-tınlı ve pH değeri yüksek olan topraklarda zeytin posasından elde edilmiş biocharın farklı dozlarının ayrı ayrı ve kükürt ile birlikte uygulanmasının; toprak enzim aktivitesi ve fosfor biyoelverişliliği üzerine etkisinin belirlenmesi için Bingöl Üniversitesi Ziraat Fakültesi İklimlendirme odasında deneme kurulmuştur. Yaş ağırlık hesabına göre her bir saksı için toplam $500 \mathrm{~g}$ olacak şekilde toprak kullanılmıştır. Denemeye başlamadan önce Zeytin posasından elde edilmiş BC materyali $100 \mathrm{~g}$ toprak için $0 \mathrm{~g}, 0.75 \mathrm{~g}$ ve $1.5 \mathrm{~g}$ olarak homojenize edilmiştir. Ayrıca, kükürt uygulaması için $0 \mathrm{mg} \mathrm{kg}^{-1}$ ve $800 \mathrm{mg} \mathrm{kg}^{-1}$ olarak kombinasyonlar oluşturulmuştur. Kontrol uygulamasında herhangi bir $B C$ ve kükürt uygulaması olmamıştır. Bu denemede İtalyan (Lollium P.) çimi bitki materyali olarak kullanılmıştır. Bu amaçla her saksıya $3 \mathrm{~kg} \mathrm{da}^{-1}$ tohum olacak şekilde ekim yapıldıktan itibaren 45 gün sonra bitkiler hasat edilmiş ve toprak örnekleri gerekli analizler için $+4{ }^{\circ} \mathrm{C}$ 'de muhafaza edilmiştir.

Faktöriyel deneme planına göre; farklı kükürt dozları $\left(\mathrm{S}_{0}(0 \mathrm{mg} / \mathrm{kg}), \mathrm{S}_{1}(800 \mathrm{mg} / \mathrm{kg})\right.$ ve farklı BC dozlarının $\mathrm{BC}_{0}(0 \%), \mathrm{BC}_{0.75}(0.75 \%), \mathrm{BC}_{1.5}(1.5 \%)$ uygulamalarının ikili kombinasyonları ile birlikte, 18 adet saksıda 3 tekerrürlü olarak yapıldı.

- $\mathrm{S}_{0} \mathrm{BC}_{0} \quad$ Kükürt (-) / Biochar (-)

- $\mathrm{S}_{0} \mathrm{BC}_{0.75}$ Kükürt (-) / Biochar (0.75\%)

- $\mathrm{S}_{0} \mathrm{BC}_{1.5}$ Kükürt (-) / Biochar (1.5\%)

- $\mathrm{S}_{1} \mathrm{BC}_{0} \quad$ Kükürt $\left(800 \mathrm{mg} \mathrm{kg}^{-1}\right) /$ Biochar (-)

- $\mathrm{S}_{1} \mathrm{BC}_{0.75} \quad$ Kükürt $\left(800 \mathrm{mg} \mathrm{kg}^{-1}\right)$ / Biochar (0.75 \%)

- $\mathrm{S}_{1} \mathrm{BC}_{1.5} \quad$ Kükürt $\left(800 \mathrm{mg} \mathrm{kg}^{-1}\right) /$ Biochar (1.5 \%)

\section{Toprak fizikokimyasal ve enzim analizleri}

10 g yas toprak örneği $105^{\circ} \mathrm{C}$ de $24 \mathrm{~h}$ etüvde kurutulduktan sonra yeniden tartılarak toprak kuru madde içeriği (Schlichting ve Blume, 1966)'e, $\mathrm{pH}$ ve elektriksel iletkenliği Richards, (1954)'e, organik madde miktarı Sherman ve ark., (2019)'e, elverişli P içeriği (Olsen ve ark., 1954), Toplam P içeriği Olsen ve Sommers, (1982)' e göre, benzer bir şekilde ekstrakte edilebilir K oranı (Richards, 1954) e göre belirlenmiştir. Toprak tekstürü (Bouyoucos, 1951)'e göre yapılmıştır. Toprakta $\mathrm{CaCO}_{3}$ oranının belirlenmesinde (Allison ve Moodie, 1965) tarafından belirtilen protokol kullanılmıştır.

Bu çalışmada 4 önemli toprak enzim aktivitesi ölçülmüştür; Toprak asit ve alkaline fosfataz enzim aktivitesi PNNP substratı kullanılarak $\mu \mathrm{g}$ pNP g toprak $\mathrm{h}^{-1}$ olarak belirlenmiştir.. Benzer şekilde, toprak $\beta$ Glukozidaz aktivitesi , $\mu$ g PNP g toprak $h^{-1}$ olarak belirlenmiştir.. Toprak dehidrogenaz enzim aktivitesi; ug TPF g toprak $24 \mathrm{~h}^{-1}$ olarak Tabatabai, (1994) tarafından belirtilen protokol kullanılmıştır.

\section{Data analizleri}

İstatistiksel analizler için SPSS 24 yazılım programı kullanılmıştır. Veriler, Faktöriyel varyans testleri kullanılarak analiz edildi. Incelenen gruplar arasında önemli farklar elde edildiğinde, Tukey HSD çoklu karşılaştırma testleri yapıldı $(p<0.05)$. Analizden önce veriler normallik ve homojenlik açısından test edildi ve bu koşulu yerine getirmek için gerektiğinde transformasyon yapılarak dönüştürüldü. Veriler normallik ve homojenlik varsayımına uymadığında, birkaç bağımsız örnek için parametrik olmayan testlerden Friedman testi uygulanarak faktöriyel varyans testleri yapılmışı $(p<0.05)$.

\section{Bulgular ve Tartışma \\ Biochar ve kükürt uygulamalarının toprakların $\mathrm{pH}$, EC ve organik madde üzerine etkileri}


$\mathrm{Bu}$ çalışmada; $\mathrm{BC}$ ve kükürt interaksiyonu $\mathrm{pH}$ üzerine etkisi istatistiksel açıdan önemsizdir (Tablo 2). Ancak; hem BC hem de S uygulamalarının ana etkisi $p<0.001$ düzeyinde istatistiksel açıdan önemli bulunuştur. S uygulaması pH oranını düşürmüştür. Aynı zamanda $\mathrm{BC}$ dozunun artmasıyla toprak $\mathrm{pH}$ oranı artmıştır. Artan BC dozu pH oranını artırmasına rağmen, $\mathrm{S}$ ile birlikte uygulanan kombinasyonlar $\mathrm{BC}_{0.75}$ ve $\mathrm{BC}_{1.5}$ dozunda $\mathrm{S}$ uygulanmayan topraklara göre \% 4.50 ile \% 5 arasında $\mathrm{pH}$ değerini düşürmüştür. En düşük $\mathrm{pH}$ oranı $(7.92 \pm 0.04)$ ile $\mathrm{BC}_{0}$ ve $\mathrm{S}_{1}$ uygulamalarında görünürken en yüksek pH oranı (8.41 \pm 0.02 ) ile $\mathrm{BC}_{1.5}$ ve $\mathrm{S}_{0}$ uygulamasında gözlemlenmiştir (Tablo 3). BC uygulamasıyla birlikte beklenildiği gibi toprak $\mathrm{pH}$ sı gibi artmıştır ve $\mathrm{S}$ uygulamasıyla bu $\mathrm{pH}$ oranı ortalama 0.4 birim düşmüştür. $\mathrm{pH}$ toprakta en önemli parametrelerden biri olup bitkilerin besin elementi alım sürecinde çok önemli rol oynamaktadır (Jaggi ve ark., 2005). Bitkiler besin elementleri en iyi (6.5-7.5) pH aralığında aldığından dolayı BC uygulanan topraklarda S uygulaması etkili olabilir. Daha önce yapılan çalışmalarda elementel $S$ uygulamasının $\mathrm{pH}$ değerini düşürdüğü (Jaggi ve ark., 2005) ve BC alkalin karakterli olduğundan dolayı toprakların $\mathrm{pH}$ oranını artırdığı ifade edilmiştir (Rousk ve ark., 2010).

$B C$ ve $S$ interaksiyonu EC üzerine etkisi $p<0.05$ düzeyinde önemli bulunmuştur (Tablo 2). Bununla birlikte EC miktarı BC dozlarının artısına bağlı olarak pozitif yönde art mistir. Buna paralel olarak, $S$ uygulaması ile birlikte; $\mathrm{EC}$ miktarı $\mathrm{BC}_{0}$ a göre; $\mathrm{BC}_{0.75}$ dozunda $\% 2$ oranında, $\mathrm{BC}_{1.5}$ dozunda \%8'lik bir artışa neden olmuştur. Ayrıca, en yüksek artış (284.6 \pm 4.33 $\mu \mathrm{Scm}^{-1}$ ) ile $\mathrm{BC}_{1.5}$ ve $\mathrm{S}_{1}$ uygulamasında görünürken, en düşük $E C$ oranı $\left(56.46 \pm 2.6 \mu \mathrm{Scm}^{-1}\right)$ ile $\mathrm{BC}_{0}$ ve $\mathrm{S}_{1}$ kombinasyonunda bulunmuştur (Tablo3). EC, Bitki gelişimi ve tuzluluk oranındaki değişimi yansıttığından dolayı, toprakların sağlığı açısından değerlendirilmesinde önemli bir parametredir (Schönegger ve ark., 2018). Bu çalışmaya paralel olarak Hashemimajd (2012) yapmış olduğu bir çalışmada kompost ve elementel $S$ uygulaması sonucunda kompost ve S interaksiyonu EC miktarını artırdığını ifade etmiştir.

$B C$ ve $S$ interaksiyonu organik madde üzerine etkisi önemli olmamasına rağmen, BC uygulamasının ana etkisi önemli ( $p<0.001)$ bulunmuştur (Tablo 2). En düşük organik madde oranı $\% 1.47$ ile $B C_{0}$ ve $S_{0}$ kombinasyonunda görünürken, en yüksek organik madde miktarı \%1.79 ile $\mathrm{BC}_{1.5}$ ve $\mathrm{S}_{0}$ uygulamasında bulunmuştur. $B C$ dozunun artmasıyla organik madde miktarında ortalama \% 21 oranında artış meydana gelmiştir (Tablo3). Topraklara BC eklenmesi toprakta C tutulmasını artırabilir ancak doğal olarak organik $C$ ayrışması sırasında BC eklemesinden kaynaklı C miktarının dikkate alınması gerekir (Jiang ve ark., 2016). Benzer şekilde yapılan bir çalışmada, BC toprak organik madde konsantrasyonunu artırmakta ve özellikle bu artış çok suda çözülebilir organik karbonun artışında görünmektedir (Lin ve ark., 2012). Buna karşın, Bruun ve EL-Zehery, (2012) yapmış oldukları bir çalışmada BC dozunun artmasıyla toprak organik karbonun mineralizasyonun yavaşladığını ifade etmişlerdir. Bu farklı etkiler, BC üretim şekli ve BC ham maddesinden kaynaklanabilir (Stewart ve ark., 2013).

\section{Biochar ve kükürt uygulamalarının toprakların elverişli $P$ ve toplam $P$ üzerine etkileri}

$B C$ ve $S$ interaksiyonu elverişli $P$ (EP) oranı üzerine etkisi istatistiksel olarak önemli bulunmamıştır. Bununla birlikte hem BC hem de $S$ uygulamalarının ana etkisi $p<0.001$ düzeyinde istatistiksel açıdan olarak önemli bulunmuştur (Tablo 2). S uygulamasıyla birlikte toprakta EP \% 59.2 oranında bir artış gözlemlenmiştir (Tablo 3). BC dozları arasında ise $\mathrm{BC}$ uygulaması yapılmayana göre: $\mathrm{BC}_{0.75}$ dozu uygulanmasıyla \% $10^{\prime}$ luk ve $\mathrm{BC}_{1.5}$ dozu uygulamasıyla bu artış \% 19.1`e kadar yükselmektedir. Uygulamalar arasında en düşük elverişli P oranı (12.82 $\pm 0.2 \mathrm{mg} \mathrm{kg}^{-1}$ ) ile $\mathrm{BC}_{0}$ ve $\mathrm{S}_{0}$ kombinasyonunda bulunurken, en yüksek $P$ oranı $\left(24.36 \pm 0.1 \mathrm{mg} \mathrm{kg}^{-1}\right)$ ile $B C_{1.5}$ ve $S_{1}$ kombinasyonunda gözlemlenmiştir (Tablo 3). Bu çalışmada S uygulamasına bağlı olarak toprak $\mathrm{pH}$ değerindeki azalmanın etkisiyle $\mathrm{P}$ biyo elverişliliğinin arttığı gözlenmektedir. Toprak $\mathrm{pH}$ oranındaki değişimin P'nin toprakta hareketliğinde ve mineralizasyonunda önemli rol oynadığı çeşitli araştırmacılar tarafından ifade edilmiştir (Bustamante ve ark., 2016). Buna karşılık toprak $P$ oranındaki değişim $B C$ ve topraktaki $P$ bazı dinamiklere göre (topraktaki EP oranı, toprağın başlangıç sorspsiyon kapasitesi ve BC içeriğinin sorpsiyon kapasitesine göre) farklılık gösterebilir (Born ø ve ark., 2018).

$B C$ ve $S$ interaksiyonun toprakların toplam $P$ (TP) üzerine etkisi önemli bulunmuştur $(p<0.001)$ (Tablo 2). En düşük toplam $P$ içeriği (727.24 $\pm 3.4 \mathrm{mg}$ $\mathrm{kg}^{-1}$ ) ile $\mathrm{BC}_{0}$ ve $\mathrm{S}_{0}$ kombinasyonunda bulunurken, en yüksek TP içeriği $\left(807.78 \pm 3.7 \mathrm{mg} \mathrm{kg}^{-1}\right)$ ile $\mathrm{S} 1-\mathrm{BC}_{1.5}$ kombinasyonunda bulunmuştur. Bu sonuçlara paralel olarak, S uygulanan topraklar S uygulanması yapılmayan topraklara göre toplam P miktarını \% 2.73 oranında arttırmıştır. Benzer şekilde, artan dozda açan $\mathrm{BC}$ uygulamasında toplam $\mathrm{P}$ miktarında artışa neden olmuştur. $\mathrm{BC}_{0.75}$ uygulaması $\mathrm{BC}$ uygulanmayan topaklara göre toplam $\mathrm{P}$ içeriğini \% 2 oranında artırımken, $\mathrm{BC}_{0.75}$ uygulaması \% 7.78 oranında art 
irmiştir. (Tablo 3). TP oranındaki artış BC doz miktarındaki artışa bağlı olarak artmıştır. Bu artış BC materyalinin sahip olduğu $P$ den kaynaklı olabilir.
Benzer şekilde (Mahmoud ve ark., 2019) yapmış olukları bir çalışmada $B C$ ve $P$ gübrelemesinin TP miktarını artırdığını ifade etmişlerdir.

Tablo 2. Farklı kükürt ve biochar uygulamaların toprakların kimyasal ve enzim aktiviteleri üzerine ana ve interaksiyonu testleri

\begin{tabular}{|c|c|c|c|c|c|c|}
\hline \multirow{2}{*}{ Parametre } & \multicolumn{2}{|c|}{ Biochar } & \multicolumn{2}{|c|}{ Kükürt } & \multicolumn{2}{|c|}{ Biochar X Kükürt } \\
\hline & $F$ & $p$ & $F$ & $p$ & $F$ & $p$ \\
\hline $\mathrm{pH}$ & 11.54 & $p<0.001$ & 878.45 & $p<0.001$ & n.s & n.s \\
\hline EC & n.s & n.s & 3435.09 & $p<0.001$ & 5.33 & $p<0.05$ \\
\hline Organik madde & 12.02 & $p<0.001$ & n.s & n.s & n.s & n.s \\
\hline Elverişli P & 49.76 & $p<0.001$ & 1027.00 & $p<0.001$ & n.s & n.s \\
\hline Total P & 166.26 & $p<0.001$ & 58.62 & $p<0.001$ & 14.89 & $p<0.001$ \\
\hline Asit Fosfataz & n.s & n.s & n.s & n.s & n.s & n.s \\
\hline Alkalin Fosfataz & n.s & n.s & n.s & n.s & n.s & n.s \\
\hline Beta Glukozidaz & n.s & n.s & 9.04 & $p<0.05$ & 4.80 & $p<0.05$ \\
\hline Dehidrogenaz & n.s & n.s & n.s & n.s & n.s & n.s \\
\hline
\end{tabular}

n.s: Önemli değil, EC: Elektriksel İletkenlik.

Tablo 3. Farklı kükürt dozu $\left(\mathrm{S}_{0} ; 0 \mathrm{mg} \mathrm{kg}{ }^{-1}, \mathrm{~S}_{1} ; 800 \mathrm{mg} \mathrm{kg}^{-1}\right)$ ve farklı biochar dozlarının $\mathrm{BC}_{0}(0 \%), \mathrm{BC}_{0.75}(0.75 \%), \mathrm{BC}_{1.5}$ (1.5\%) toprakların pH, EC, Organik madde, Elverişli fosfor ve Toplam fosfor üzerine etkileri.

\begin{tabular}{cllllll}
\hline \multicolumn{2}{c}{ Uygulamalar } & \multicolumn{5}{c}{ Parametreler } \\
\hline \multirow{2}{*}{ Kükürt } & Biochar & \multicolumn{1}{c}{$\mathbf{p H}$} & EC $(\boldsymbol{\mu S} / \mathbf{c m})$ & Organik madde (\%) & $\begin{array}{c}\text { Elverişli P } \\
\left(\mathbf{m g ~ k g}^{-1}\right)\end{array}$ & $\begin{array}{c}\text { Toplam } \mathbf{P} \\
\left(\mathbf{m g ~ k g}^{-1}\right)\end{array}$ \\
\hline \multirow{3}{*}{$\mathrm{S}_{0}$} & $\mathrm{BC}_{0}$ & $8.31 \pm 0.01 \mathrm{~b}$ & $56.4 \pm 2.6 \mathrm{a}$ & $1.47 \pm 0.07 \mathrm{a}$ & $12.82 \pm 0.2 \mathrm{a}$ & $734.4 \pm 3.4 \mathrm{a}$ \\
& $\mathrm{BC}_{0.75}$ & $8.33 \pm 0.01 \mathrm{bc}$ & $59.8 \pm 3.3 \mathrm{a}$ & $1.61 \pm 0.07 \mathrm{ab}$ & $14.23 \pm 0.5 \mathrm{ab}$ & $738.7 \pm 0.7 \mathrm{ab}$ \\
& $\mathrm{BC}_{1.5}$ & $8.41 \pm 0.02 \mathrm{c}$ & $61.0 \pm 2.7 \mathrm{a}$ & $1.79 \pm 0.03 \mathrm{~b}$ & $15.61 \pm 0.2 \mathrm{~b}$ & $767.0 \pm 3.9 \mathrm{c}$ \\
\hline \multirow{3}{*}{$\mathrm{S}_{1}$} & $\mathrm{BC}_{0}$ & $7.92 \pm 0.01 \mathrm{a}$ & $262.9 \pm 7.7 \mathrm{~b}$ & $1.47 \pm 0.03 \mathrm{a}$ & $20.73 \pm 0.4 \mathrm{c}$ & $727.2 \pm 2.8 \mathrm{a}$ \\
& $\mathrm{BC}_{0.75}$ & $7.95 \pm 0.01 \mathrm{a}$ & $264.4 \pm 3.5 \mathrm{bc}$ & $1.54 \pm 0.03 \mathrm{ab}$ & $22.88 \pm 0.1 \mathrm{~d}$ & $750.3 \pm 3.0 \mathrm{~b}$ \\
& $\mathrm{BC}_{1.5}$ & $7.97 \pm 0.01 \mathrm{a}$ & $284.5 \pm 4.3 \mathrm{c}$ & $1.69 \pm 0.04 \mathrm{ab}$ & $24.36 \pm 0.1 \mathrm{~d}$ & $807.7 \pm 3.7 \mathrm{~d}$ \\
\hline
\end{tabular}

Farklı harfler, her kükürt ve biochar uygulama işleminin interaksiyonu veya ana faktörün etkisine göre: Tukey posthoc testinin sonuçlarını göstermektedir. Değerler kuru ağırlık (FKA) bazında $n=3$ (ortalama \pm standart hata) olarak verilmiştir.

\section{Biochar ve kükürt uygulamalarının asit fosfataz, alkalin fosfataz, dehidrogenaz ve b-glukozidaz enzim aktiviteleri üzerine etkileri}

$\mathrm{Bu}$ çalışmada S ve BC uygulamalarının farklı toprak enzim aktivitesi üzerindeki etkileriyle ilgili olarak, $\mathrm{S}$ ve $\mathrm{S}$ uygulamaları olmadığı durumlarda $\beta$ glukozidaz enzim aktivitesi dışında $(p<0.05)$ istatistiksel açıdan önemli hiçbir etki gözlenmedi (Tablo 2). Incelenen enzimlerden 3 tanesi, yani asit fosfataz (AcdP), alkalin fosfataz (AlkP) ve dehidrogenaz (DH) üzerine $B C$ dozları ve $S$ uygulamaları farklı aktiviteler göstermiştir (Şekil 1). Bununla birlikte, en yüksek AcdP aktivitesi (75.6 \pm 4.3 $\mu \mathrm{g}$ pNP g FKA ${ }^{1}$ saat $^{-1}$ ) ile $\mathrm{BC}_{0.75}$ ve $S_{1}$ kombinasyonunda gözlemlenirken en düşük AcdP aktivitesi $(65.2 \pm 0.2 \mu \mathrm{g}$ pNP g FKA ${ }^{-1}$ saat $^{-1}$ ) ile $\mathrm{BC}_{1.5}$ ve $\mathrm{S}_{0}$ kombinasyonunda bulunmuştur. Bu sonuca paralel olarak, en yüksek AlkP aktivitesi $\left(189.2 \pm 0.2 \mu \mathrm{g}\right.$ pNP g FKA ${ }^{-1}$ saat $\left.^{-1}\right)$ ile
$\mathrm{BC}_{1.5}$ ve $\mathrm{S}_{0}$ kombinasyonunda gözlemlenirken, en düşük AlkP konsantrasyonu (143 $\pm 27.1 \mu \mathrm{g}$ pNP g FKA ${ }^{1}$ saat $^{-1}$ ) ile $\mathrm{BC}_{0}$ ve $\mathrm{S}_{0}$ kombinasyonunda bulunmuştur. Dehidrogenaz enzim aktivitesi en yüksek (29.13 \pm 1.1 $\mu \mathrm{g}$ TPF g FKA ${ }^{-1} 24^{-1}$ ) ile $\mathrm{BC}_{0}$ ve $\mathrm{S}_{1}$ kombinasyonunda gözlemlenirken, en düşük $\mathrm{DH}$ enzim aktivitesi $\left(13.48 \pm 1.2 \mu \mathrm{g}\right.$ TPF g $\mathrm{FKA}^{-1} 2^{24}{ }^{1}$ ) ile $\mathrm{BC}_{0}$ ve $\mathrm{S}_{0}$ kombinasyonunda gözlemlenmiştir (Sekil 1). Bu 3 enzim aktivitesi dışında, $\beta$-glukozidaz enzim aktivitesi üzerine $B C$ ve $S$ interaksiyonu önemli çıkmıştır $(P<0.05)$. S uygulaması ile $\beta$ - Glu aktivitesi $S$ uygulaması yapılmayan topraklara göre enzim aktivitesini \%16.01 oranında azaltmıştır. Bununla birlikte en yüksek $\beta$-glukozidaz aktivitesi (49.44 \pm 1.78 $\mu \mathrm{g}$ pNP g FKA ${ }^{-1}$ saat $^{-1}$ ) ile $\mathrm{BC}_{0}$ ve $\mathrm{S}_{0}$ kombinasyonunda bulunurken, en düşük $\beta$ - Glu enzim aktivitesi (33.65 \pm $1.23 \mu \mathrm{g}$ pNP g $\mathrm{FKA}^{-1}$ saat $^{-1}$ ) ile $\mathrm{BC}_{0}$ ve $\mathrm{S}_{1}$ kombinasyonlarında bulunmuştur. Enzim aktiviteleri 
sürdürülebilir toprak yönetimi uygulamalarında hızlı bir tepki gösterdiğinden dolayı toprak sağı̆̆ı açısından önemli bir parametredir. Bununla birlikte AcdP ve AlkP fosfataz enzim aktivitesi Organik fosforun mineraliz olup fosfata dönüşme sürecinde anahtar bir rol oynamaktadır (Nannipieri ve ark., 2011). BC uygulamasının AlkP aktivitesi üzerine yapılan çalışmalarda; (Akça ve Namlı, 2015) AlkP ve AcdP aktivitesini artığını, (Noyce ve ark., 2017). AlkP aktivitesini azalttığını, bununla birlikte bizim çalışmamızda olduğu gibi (Zhang ve ark., 2017) tarafından yapılan bir çalışmada AlkP aktivitesini etkilemediğini belirtmişlerdir. Benzer şekilde $\mathrm{DH}$ aktivitesi üzerine $B C$ ve $S$ uygulamasının etkisi görünmemiştir. (Khadem veRaiesi, 2019) yapmış oldukları çalışmada iki farklı tekstüre sahip kireçli topraklarda BC uygulanmasiyla potansiyel dehidrogenaz enzim aktivitesinin değiştiğini ancak bu artışın kumlu topraklara göre killi topraklarda daha az olduğunu ifade etmişlerdir. Bu sonuçlar gösteriyor ki C formunda eklenen BC zor ayrışabilir olması sonucu DH aktivitesinde farklılık olmayabilir (Wu ve ark., 2013), toprak tipine göre DH enzim aktivitesi farklılık gösterebilir (Khadem ve Raiesi, 2019). Diğer 3 enzimin dışında $\beta$ - Glu enzim aktivitesi üzerine $B C$ ve $S$ interaksiyonu önemli çıkmıştır. İnteraksiyonun nedeni topraklara uygulanan $\mathrm{BC}$ ve $\mathrm{S}$ uygulamalarının toprağın kimyasal özelliklerini etkilemesiyle olabilir. Buna karşılık Bailey ve ark., 2011 yapmış olduğu çalışmada, toprak tipinin $\beta$ - Glu enzim aktivitesini etkilediğini ifade etmiştir.
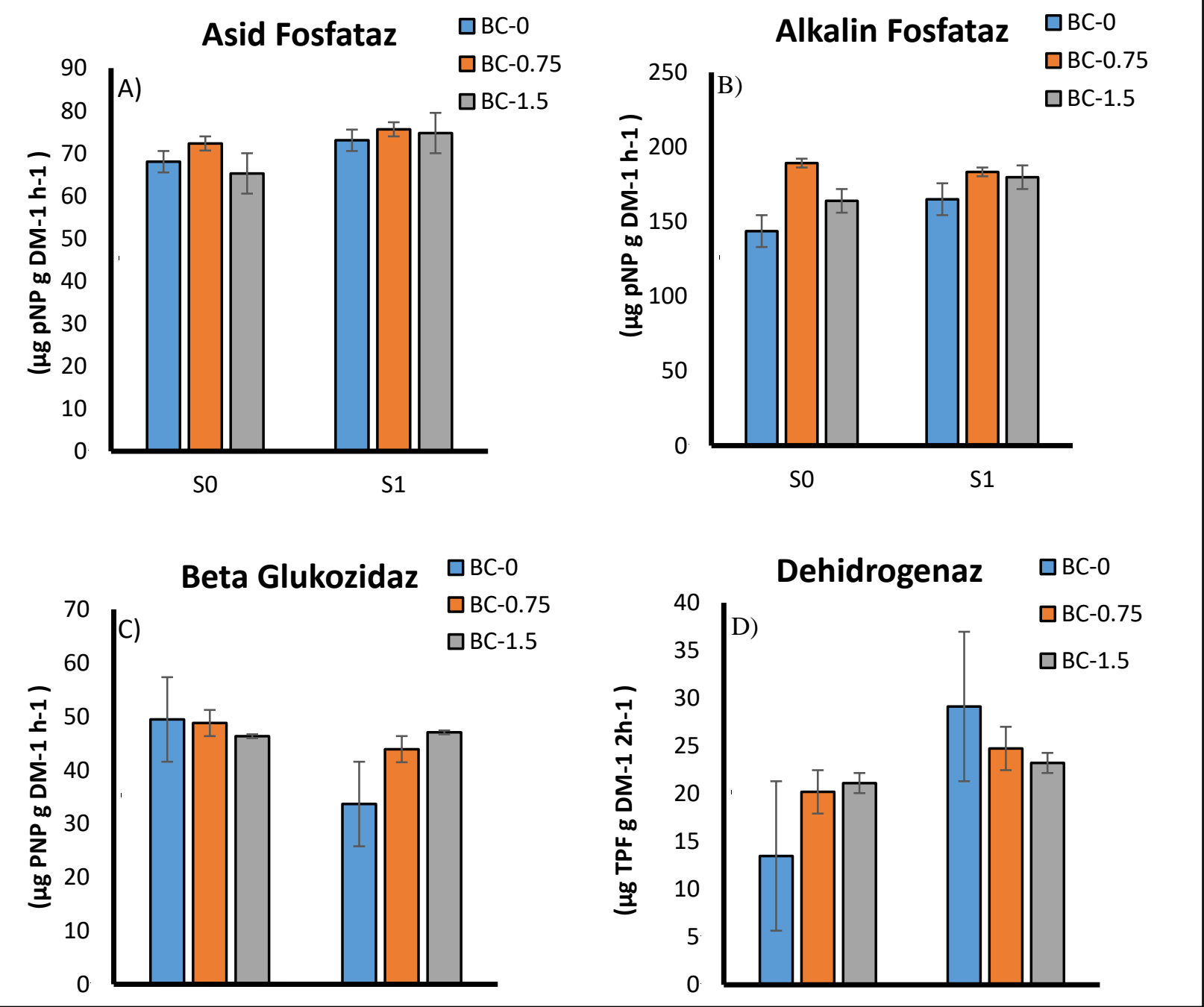

Şekil 1. Farklı kükürt dozu (S0: $\mathrm{mg} \mathrm{kg}^{-1}$. S1: $800 \mathrm{mg} \mathrm{kg}^{-1}$ ) ve farklı biochar dozlarının; $\mathrm{BC}_{0}\left(0\right.$ \%). $\mathrm{BC}_{0.75}\left(0.75 \%\right.$ \%). $\mathrm{BC}_{1.5}$ (1.5\%) toprakların A) Asit fosfataz (B) Alkalin fosfataz C) $\beta$-glukozidaz ve D) Dehidrogenaz enzim aktivesi üzerine etkileri. Değerler kuru ağırlık (FKA) bazında $n=3$ (ortalama \pm standart hata) olarak verilmiştir. 


\section{Sonuç ve Öneriler}

Bu araştırma açıkça zeytin posasından elde edilen $B C^{\prime}$ nin $S$ ile birlikte uygulanmasının toplam fosfor değerini arttırdığını göstermektedir. Ayrıca, hem $B C$ hem de $S$ uygulamaları elverişli $P$ miktarını artırmıştır. Bununla birlikte, $B C$ ve $S$ kombinasyonu toprak EC değerinde artışa neden olurken $\mathrm{S}$ uygulanan topraklarda $\mathrm{pH}$ değeri düşmüştür. Topraktaki organik madde miktarı BC dozunun artmasıyla yükselmiştir. Dikkat çekici bir şekilde $B C$ ve $S$ uygulamaları; asit fosfataz, alkalin fosfataz ve dehidrogenaz enzim aktivitesi üzerine etki yapmazken, BC uygulaması yapılmayan $S$ uygulamasında $\beta$-glukozidaz enzim aktivitesi azalmıştır. Bu ön çalışmanın sonuçlarına dayanarak $B C$ ve $S$ uygulamalarının farklı toprak tiplerinde ve arazi koşullarında da araştırılması gerekmektedir.

\section{Kaynaklar}

Akça, M.O., Namlı, A. 2015. Effects of poultry litter biochar on soil enzyme activities and tomato, pepper and lettuce plants growth. EURASIAN J. SOIL Sci. EJSS, 4: 161-168. https://doi.org/10.18393/ejss.2015.3.161-168

Allison, L.E., Moodie, C.D. 1965. Carbonate, in: In Methods of Soil Analysis. Agronomy No. 9, Part 2. Ed. C A Black American Society of Agronomy, Inc., Madison, Wisconsin, pp. 1379-1396.

Bailey, V.L., Fansler, S.J., Smith, J.L., Bolton, H. 2011. Reconciling apparent variability in effects of biochar amendment on soil enzyme activities by assay optimization. Soil Biol. Biochem., 43: 296-301.

Bornø, M.L., Müller-Stöver, D.S., Liu, F. 2018. Contrasting effects of biochar on phosphorus dynamics and bioavailability in different soil types. Sci. Total Environ., 627: 963-974. https://doi.org/10.1016/j.scitotenv.2018.01.2 83.

Bouyoucos, G.J. 1951. A Recalibration of the hydrometer method for making mechanical analysis of soils 1. Agron. J., 43: 434. https://doi.org/10.2134/agronj1951.0002196 $2004300090005 x$.

Bruun, S., El-Zehery, T. 2012. Biochar effect on the mineralization of soil organic matter. Pesqui. Agropecuária Bras., 47: 665-671.

Bustamante, M.A., Ceglie, F.G., Aly, A., Mihreteab, H.T., Ciaccia, C., Tittarelli, F. 2016. Phosphorus availability from rock phosphate: Combined effect of green waste composting and sulfur addition. J. Environ. Manage., 182: 557-563.
Carpenter, S.R. 2008. Phosphorus control is critical to mitigating eutrophication. Proc. Natl. Acad. Sci., 105: 11039-11040.

Cordell, D., Drangert, J.O., White, S. 2009. The story of phosphorus: Global food security and food for thought. Glob. Environ. Change, 19: 292-305.

Dick, W.A., Cheng, L., Wang, P. 2000. Soil acid and alkaline phosphatase activity as $\mathrm{pH}$ adjustment indicators. Soil Biol. Biochem. 32: 1915-1919.

Ding, Y., Liu, Y., Liu, S., Li, Z., Tan, X., Huang, X., Zeng, G., Zhou, L., Zheng, B. 2016. Biochar to improve soil fertility. A review. Agron. Sustain. Dev., 36: 36.

Islam, M. 2012. The effect of different rates and forms of sulfur on seed yield and micronutrient uptake by chickpea. Plant Soil Environ., 58: 399-404.

Jaggi, R.C., Aulakh, M.S., Sharma, R. 2005. Impacts of elemental $S$ applied under various temperature and moisture regimes on $\mathrm{pH}$ and available $\mathrm{P}$ in acidic, neutral and alkaline soils. Biol. Fertil. Soils, 41: 52-58.

Jiang, X., Haddix, M.L., Cotrufo, M.F. 2016. Interactions between biochar and soil organic carbon decomposition: Effects of nitrogen and low molecular weight carbon compound addition. Soil Biol. Biochem., 100: 92-101.

Hashemimajd, K. 2012. Effect of elemental sulphur and compost on $\mathrm{pH}$, electrical conductivity and phosphorus availability of one clay soil. Afr. J. Biotechnol., 11:. https://doi.org/10.5897/AJB11.2800.

Khadem, A., Raiesi, F. 2019. Response of soil alkaline phosphatase to biochar amendments: Changes in kinetic and thermodynamic characteristics. Geoderma, 337: 44-54. https://doi.org/10.1016/j.geoderma.2018.09. 001.

Lehmann, J., Rillig, M.C., Thies, J., Masiello, C.A., Hockaday, W.C., Crowley, D. 2011. Biochar effects on soil biota - A review. Soil Biol. Biochem., 43: 1812-1836. https://doi.org/10.1016/j.soilbio.2011.04.022.

Lehmann, J., Joseph, S. 2015. Biochar for Environmental Management: Science, Technology and Implementation. Taylor \& Francis.

Lin, Y., Munroe, P., Joseph, S., Henderson, R., Ziolkowski, A. 2012. Water extractable organic carbon in untreated and chemical treated biochars. Chemosphere, 87: 151-157. 
https://doi.org/10.1016/j.chemosphere.2011. 12.007 .

Mahmoud, E., Ibrahim, M., Abd El-Rahman, L., Khader, A. 2019. Effects of Biochar and Phosphorus Fertilizers on Phosphorus Fractions, Wheat Yield and Microbial Biomass Carbon in Vertic torrifluvents. Commun. Soil Sci. Plant Anal., 50: 362-372. https://doi.org/10.1080/00103624.2018.1563 103.

Nannipieri, P., Giagnoni, L., Landi, L., Renella, G. 2011. Role of Phosphatase Enzymes in Soil, in: Bünemann, E., Oberson, A., Frossard, E. (Eds.), Phosphorus in Action. Springer Berlin Heidelberg, Berlin, Heidelberg, pp. 215-243. https://doi.org/10.1007/978-3-642-15271-

9_9.

Noyce, G., Jones, T., Fulthorpe, R., Basiliko, N. 2017. Phosphorus uptake and availability and shortterm seedling growth in three Ontario soils amended with ash and biochar. Can. J. Soil Sci., https://doi.org/10.1139/CJSS-2017-0007.

Olsen, S.R., Cole, C.V., Watanable, F.S., Dean, L.A. 1954. Estimation of available phosphorus in soils by extraction with sodium bicarbonate. Wash. DC US Dep. Agric., 939: 19.

Olsen, S.R., Sommers, L.E. 1982. Phosphorus, in: In: Page, A.L., Ed., Methods of Soil Analysis Part 2, Chemical and Microbiological Properties. American Society of Agronomy, Soil Science Society of America, Madison, pp. 403-430.

Richards, L.A. 1954. Diagnosis and Improvement of Saline and Alkali Soils. In: USDA Hand Book. United States Salinity Laboratory, Washington, USA.

Rousk, J., Brookes, P.C., Bååth, E. 2010. The microbial PLFA composition as affected by $\mathrm{pH}$ in an arable soil. Soil Biol. Biochem., 42: 516-520. https://doi.org/10.1016/j.soilbio.2009.11.026.

Schlichting, E., Blume, H.P. 1966. Bodenkundliches Praktikum. In Parley, Hamburg.

Schönegger, D., Gómez-Brandón, M., Mazzier, T., Insam, H., Hermanns, R., Leijenhorst, E., Bardelli, T., Fernández-Delgado Juárez, M. 2018. Phosphorus fertilising potential of fly ash and effects on soil microbiota and crop. Resour. Conserv. Recycl., 134: 262-270. https://doi.org/10.1016/j.resconrec.2018.03.0 18.

Sherman, C., Unc, A., Doniger, T., Ehrlich, R., Steinberger, Y. 2019. The effect of human trampling activity on a soil microbial community at the Oulanka Natural Reserve,
Finland. Appl. Soil Ecol., 135: 104-112. https://doi.org/10.1016/j.apsoil.2018.11.013.

Sonmez, O., Turan, V., Kaya, C. 2016. The effects of sulfur, cattle, and poultry manure addition on soil phosphorus. Turk. J. Agric. For., 40: 536541. https://doi.org/10.3906/tar-1601-41.

Stewart, C.E., Zheng, J., Botte, J., Cotrufo, M.F. 2013. Co-generated fast pyrolysis biochar mitigates green-house gas emissions and increases carbon sequestration in temperate soils. GCB Bioenergy, 5: 153-164. https://doi.org/10.1111/gcbb.12001.

Sun, D., Hale, L., Kar, G., Soolanayakanahally, R., Adl, S. 2018. Phosphorus recovery and reuse by pyrolysis: Applications for agriculture and environment. Chemosphere, 194: 682-691. https://doi.org/10.1016/j.chemosphere.2017. 12.035.

Tabatabai, M.A. 1994. Soil Enzymes, in: Methods of Soil Analysis: In R. W. Weaver, J. S. Angle, \& P. S. Botttomley (Eds.),. WI: Soil Science Society of America, Madison, Wisconsin, pp. 775-833.

Turan, V., Khan, S.A., Mahmood-ur-Rahman, Iqbal, M., Ramzani, P.M.A., Fatima, M. 2018 a. Promoting the productivity and quality of brinjal aligned with heavy metals immobilization in a wastewater irrigated heavy metal polluted soil with biochar and chitosan. Ecotoxicol. Environ. Saf., 161: 409-419. https://doi.org/10.1016/j.ecoenv.2018.05.082

Turan, V., Ramzani, P.M.A., Ali, Q., Abbas, F., Iqbal, M., Irum, A., Khan, W.D. 2018b. Alleviation of nickel toxicity and an improvement in zinc bioavailability in sunflower seed with chitosan and biochar application in $\mathrm{pH}$ adjusted nickel contaminated soil. Arch. Agron. SOIL Sci., 64: 1053-1067. https://doi.org/10.1080/03650340.2017.1410 542.

Van Vuuren, D.P., Bouwman, A.F., Beusen, A.H.W. 2010. Phosphorus demand for the $1970-2100$ period: A scenario analysis of resource depletion. Glob. Environ. Change, 20: 428-439. https://doi.org/10.1016/j.gloenvcha.2010.04. 004.

Wu, F., Jia, Z., Wang, S., Chang, S.X., Startsev, A. 2013. Contrasting effects of wheat straw and its biochar on greenhouse gas emissions and enzyme activities in a Chernozemic soil. Biol. Fertil. Soils, 49: 555-565. https://doi.org/10.1007/s00374-012-0745-7. 
Zhang, M., Cheng, G., Feng, H., Sun, B., Zhao, Y., Chen, H., Chen, J., Dyck, M., Wang, X., Zhang, J., Zhang, A. 2017. Effects of straw and biochar amendments on aggregate stability, soil organic carbon, and enzyme activities in the Loess Plateau, China. Environ. Sci. Pollut. Res., 24: 10108-10120.

https://doi.org/10.1007/s11356-017-8505-8. 